International Review of Social History 43 (1998), Supplement, pp. 9-32

(C) 1998 Internationaal Instituut voor Sociale Geschiedenis

\title{
Temporally Recursive Regression and Social Historical Inquiry: An Example of Cross-Movement Militancy Spillover*
}

\author{
Larry Isaac, Larry Christiansen, Jamie Miller and Tim \\ NICKEL
}

Our focus here is on time-series regression as a formal analytic tool in social historical inquiry. We have three interrelated purposes. First, we argue that conventional time-series regression is typically ill-suited for social historical inquiry because ahistorical assumptions and conventions regarding time undermine the historical character of social "process-as-analyzed". Second, we present a modified time-series approach - temporally recursive regression - that takes time seriously and provides a more adequate analytic vehicle for social historical inquiry. Finally, we illustrate the promise of temporally recursive regression by using it to analyze how workplace militancy in post-war America was fueled by massive insurgency waves during successive phases of the civil rights movement.

\section{AHISTORICAL CHARACTER OF CONVENTIONAL TIME-SERIES REGRESSION ${ }^{\text {I }}$}

Conventional time-series regression contains a conception of time that is ahistorical in character. ${ }^{2}$ It is fairly termed ahistorical, we believe, because time enters the analysis solely as a means of analysis, an instrumental marker for purposes of ordering the time unit observations (e.g. years). Treating time, and therefore history, as simply means rather than also object of analysis shapes the practice of conventional time-series regression in such a way that unduly masks significant historical context, meaning and nuance in social process. Simply put, ahistorical time severely limits what conventional

\footnotetext{
* We thank Larry Griffin and Marcel van der Linden for comments on prior versions of the paper. Isaac's co-authors are listed in alphaberical order.

I. This section draws on: Larry Isaac and Larry Griffin, "Ahistoricism in Time-Series Analyses of Historical Process: Critique, Redirection, and Illustrations from U.S. Labor History", American Sociological Review, 54 (1989), pp. 873-890; Larry Griffin and Larry Isaac, "Recursive Regression and the Historical Use of 'Time' in Time-Series Analysis of Historical Process", Historical Methods, 25 (1992), pp. 166-179; Larry Isaac and Kevin Leicht, "Regimes of Power and the Power of Analytic Regimes: Explaining U.S. Military Procurement Keynesianism as Historical Process", Historical Methods, 30 (1997), pp. 28-45.

2. On forms of temporality in social historical inquiry, see William Sewell, "Three Temporalities: Toward an Eventful Sociology", in Terrence McDonald (ed.). The Historic Turn in the Human Sciences (Ann Arbor, MI, 1996), pp. 245-280.
} 
time-series regression can contribute to social historical inquiry, both in terms of mapping past historical processes and what it can offer for theoretical development.

The acceptance of ahistorical time leads to two interrelated practices that produce much of the damage. One rests on the analytical use of a single, fixed time frame. Data representing the process of interest are organized into and analyzed over a fixed time period without regard to historical aspects of starting, ending or intervening time points. Opening and ending dates are arbitrarily selected, then the model is estimated on a single time frame. The potential value to historical inquiry of varying the start/end points is not anticipated (usually the question is not even raised) and is, therefore, not explored.

A related convention - known as the homogeneity assumption - assumes that the regression coefficients linking a dependent variable to a set of independent variables are identical for each and every time point contained within the fixed time frame. Several significant ahistorical implications stem from this assumption. First, transhistorically general parameter estimates are produced as single numerical representations of causal impact over quite lengthy periods of history. Consequently historical documentation and extant analysis of how social contexts and events might condition or alter the causal processes of interest are simply ruled out by methodological fiat. The only source of social change posited within such a model occurs as quantitative variation in the dependent variable. Other, perhaps deeper, forms of social change that might register in the process structure (structural form of the model) or parameter structure (coefficients linking independent to dependent variables) are treated as historical constants. ${ }^{3}$

Second, the homogeneity assumption masks the existence of unusual time periods, especially active moments that form historical turning points in a particular process. "Exceptional" (or "deviant") cases are routinely treated as obstacles rather than as important theoretical-historical anomalies to be explained. As such, they are often ignored or eliminated. An image of seamless historical continuity is created, again by methodological fiat, rather than empirically detected and explained. Consequently, theories that posit important historical discontinuities and/or feature the transformative potential of events and human agency are unlikely to find inspiration or support from conventional time-series analyses. Moreover, when historical contexts and events do, in fact, affect the causal relationships between independent and dependent variables, the opposite a priori assumption is likely to generate seriously misguided inferences.

3. For more detail on sources of constancy and change within time-series models, see Thomas Janoski and Larry Isaac, "Introduction to Time-Series Analysis", in Thomas Janoski and Alexander Hicks (eds), The Comparative Political Economy of the Welfare State (Cambridge, 1994), pp. 31-53, Table I. 
Third, the homogeneity assumption licenses the analyst to "slice into" history at any convenient point. Under this assumption it makes no difference where one begins or ends the analysis since the time-series observations are understood to be manifestations of the same underlying continuous process. Encouraged by assumptions of theoretical generality and historical invariance, analyses driven exclusively by data availability can be easily justified. The findings of such studies are situated in periods defined by happenstance of data availability, or perhaps even the desire to extend the number of time points to meet technical "sample" size requirements or to enhance statistical significance. In such instances, history has been literally reduced to "merely a storehouse of samples" ${ }^{4}$

In combination the fixed time frame and homogeneity assumptions profoundly shape the results and, therefore, inferences drawn within conventional time-series analyses. ${ }^{5}$ Causal models are uncritically presented as time (and therefore historically) invariant. At minimum, this leads to an underestimation of how potentially heterogeneous historical contexts, human actions and events condition social processes and alter possibilities for future action. By extension it reinforces images of seamless historical continuity already dominant in much social science theory and quantitative research. ${ }^{6}$

\section{HISTORICIZING TIME-SERIES REGRESSION ANALYSIS ${ }^{7}$}

Temporally recursive regression (TRR) - also known as "moving regression" - was originally developed to empirically examine the validity of the parameter homogeneity assumption. ${ }^{8}$ Its procedures also necessarily relax the fixed time frame convention. Although not initially developed as a historically-oriented research tool, TRR can be historicized in a manner that allows it to be used with good result in social historical research employing time-series data. By historicization of method, we mean that

4. Barrington Moore, Political Power and Social Theory (Cambridge, MA, 1958), p. I13.

5. Another important temporal issue in time-series analysis of historical process is time unit (scale) aggregation: see Gary F. Jensen, "Time and Social History: Problems of Atemporality in Historical Analyses with Illustrations from Research on Early Modern Witch Hunts", Historical Methods, 30 (1997), pp. 46-57.

6. Larry Isaac, "Transforming Localities: Reflections on Time, Causality, and Narrative in Contemporary Historical Sociology", Historical Methods, 30 (1997), pp. 4-I2.

7. This section draws on: Isaac and Griffin, "Ahistoricism in Time-Series Analyses", pp. 873-90; Griffin and Isaac, "Recursive Regression", pp. 166-79; Isaac and Leicht, "Regimes of Power", pp. 28-45.

8. Procedures for testing the homogeneity assumption are discussed in Richard Quandt, "The Estimation of the Parameters of a Linear Regtession System Obeying Two Separate Regimes", Journal of the American Statistical Association, 53 (1958), pp. 873-80; and R.L. Brown, J. Durbin and J.M. Evans, "Techniques for Testing the Constancy of Regression Relations Over Time", Journal of the Royal Statistical Society, 37 (1975), pp. I49-192. The term "moving regression" is due to Brown et al. 
research technique and its central premises should be subordinated to the historical and substantive terms of the analysis, not the reverse as is the case in conventional time-series practice.

TRR belongs to a family of procedures known as "time-varying" or "stochastic" parameter models" that are designed to allow relationships between dependent and independent variables to change through time. Such models can be estimated in a variety of different ways, some of which embody rather complex mathematics and require highly restrictive a priori theoretical assumptions about the historical process under investigation. We prefer TRR and limit our discussion to it for several important reasons: first, it is relatively simple to use and understand; second, it contains fewer restrictive assumptions than even conventional time-series regression (i.e. the fixed parameter assumption is relaxed); and third, one of its strategic forms (the "forward" version discussed below) is available as an automated routine in several regression programs (TSP, PC-GIVE, EVIEWS) while others can be programmed to do it (e.g. RATS).

While TRR has been used with increasing frequency in recent years, it is still a fringe approach relative to conventional regression analysis. Thus, several key issues should be considered by scholars contemplating the use of TRR: ( $\mathrm{I}$ ) basic procedural logics in relation to the research question of interest; (2) ability to map various dimensions of social historical change; and (3) specific contributions to social historical inquiry.

\section{Basic procedural logics of TRR}

The historicization of time-series analysis can be accomplished through TRR because it facilitates the historicization of time. It does so by presupposing the potentially unique historical value of particular temporal moments, either in terms of analytic start/end points defining the time frame of analysis or as turning points in relations governing the social historical process. This can be most clearly seen in the procedural logic of TRR. Instead of centering the analysis on a fixed time frame, TRR systematically moves the time frame through different start and/or end points bracketing the historical periods of investigation. This simple relaxation of conventional practice allows (but does not force) the estimated parameter structure to change as the time points defining historical periods are changed by the analyst.

Three different TRR strategies define how one alters the start and/or end points of the time frame containing the numerical series. An initial sub-

9. See L.W. Johnson, "Stochastic Parameter Regression: An Annotated Bibliography", International Statistical Review, 45 (1977), pp. 257-272; Nathaniel Beck, "Time-Varying Parameter Regression Models", American Journal of Political Science, 27 (1983), pp. 557-600; P. Newbold and T. Bos, Stochastic Parameter Regression Models (Beverly Hills, CA, 1985). 
Table I. Structure of a hypothetical temporally recursive regression: three analytic strategies, $1948-198 I$

\begin{tabular}{|c|c|c|}
\hline & Panel A: Forward-moving strategy & \\
\hline Time frame & & Coefficient \\
\hline $1948-1960$ & & $b_{48-60}$ \\
\hline $1948-1961$ & & $b_{48-61}$ \\
\hline $1948-1962$ & & $b_{48-62}$ \\
\hline $1948-1979$ & & $b_{48-79}$ \\
\hline $1948-1980$ & & $b_{48-80}$ \\
\hline $1948-1981$ & & $b_{48-81}$ \\
\hline & Panel B: Backward-moving strategy & \\
\hline Time frame & & Coefficient \\
\hline $1969-1981$ & & $b_{69-81}$ \\
\hline $1968-1981$ & & $b_{68-81}$ \\
\hline $1967-1981$ & & $b_{67-81}$ \\
\hline $1950-1981$ & & $b_{50-81}$ \\
\hline 1949-1981 & & $b_{49-81}$ \\
\hline $1948-1981$ & & $\mathrm{~b}_{48-81}$ \\
\hline & $\begin{array}{l}\text { Panel C: Diagonal-moving strategy } \\
\text { (using an eleven-year time frame) }\end{array}$ & \\
\hline Time frame & & Coefficient \\
\hline $1948-1958$ & & $\mathrm{~b}_{48-58}$ \\
\hline $1949-1959$ & & $\mathrm{~b}_{49-59}$ \\
\hline $1950-1960$ & & $b_{50-60}$ \\
\hline $1969-1979$ & & $b_{69-79}$ \\
\hline $1970-1980$ & & $b_{70-80}$ \\
\hline $1971-1981$ & & $b_{71-81}$ \\
\hline
\end{tabular}

Note: This is a restylized version of Table I in Griffin and Isaac, "Recursive Regression", p. 169 .

period must be selected for the first estimation in each analytic strategy. Because starting and ending points are assumed to be potentially important to the analysis, the initial sub-period should be specified on the basis of sound historical-theoretical insight regarding likely homogeneity of causal relations within that sub-period. Later we illustrate an empirical application of TRR in an investigation of a social movement spillover spanning the years 1948 to $198 \mathrm{r}$. Here we outline the analytic logic of TRR using those years as reference points.

The forward-moving strategy anchors the analysis with the first year in the series (1948), defines an initial sub-period for first estimation (1948-1960), and then repeats the estimation process seriatim by adding one new year to the time frame until the final estimation utilizes all time points in the series (1948-1961, I948-1962,.., 1948-198I). The structure of the forwardmoving strategy is shown in Panel A of Table $\mathrm{I}$. 
Panel B displays the backward-moving strategy. Here the analysis is anchored at the most recent year (198I) and the start point is allowed to increment backward in time, from 1969 to 1948 . In other words, the initial estimation would include the years 1969 to $198 \mathrm{r}$ as the time frame, the second estimation would cover 1968 to 1981 , and so on until the earliest year in the series, 1948 , is part of the estimation time frame.

The third TRR strategy fixes the number of time points (i.e. years) in the time frame to be analyzed. The example in Panel $\mathrm{C}$ uses a period length of eleven years. The analyst then varies the start and end points simultaneously with each estimation (e.g. 1948-1958, 1949-1959, . . , 1970-1980, $197 \mathrm{I}-198 \mathrm{I})$. This is the diagonal-moving strategy.

In general, if the equation to be estimated contains one dependent variable and $\mathrm{K}$ explanatory variables to be estimated on $\mathrm{P}$ sub-periods, the analyst will, in effect, produce a PxK matrix of coefficients. While important practical issues will arise (discussed below), nothing extraordinary is required in terms of estimation technique per se: any appropriate estimator - ordinary least squares (OLS) or generalized least squares (GLS) variant - may be employed.

It is important to recognize that there is no single "truth" to be found from TRR. The three approaches - forward, backward, diagonal - posit different underlying questions and therefore generate different answers about historical processes and social change. Therefore, parameter regimes estimated by different strategies will not necessarily coincide with each other.

Because the forward strategy anchors the time frame at the historically most distant point in the series and then serially expands the time frame forward, it is most fruitfully employed when the analyst is interested in the "development" (continuous or discontinuous) of the historical process. Therefore, an example of this sort of question might be: "Given a particular structure of (causal) relations at an earlier period in history, how did subsequent historical actions and events affect (if at all) the trajectory of the relations of interest?" The backward strategy, however, is best suited to issues concerning the historical antecedents of present (any "present") historical conditions, structure and causal patterns. One type of question that might motivate this strategy would be: "At what point (if any) in the past was there a structural shift in which the current parameter structure became 'institutionalized' as a governing regime?" As the observations are expanded forward or backward in time, the analytic distinctions between these two strategies become moot as they converge on the same full time frame.

The diagonal procedure can serve as a useful check on the results obtained with either the forward or backward approaches. Unlike its counterparts, the diagonal approach will produce cross-temporal parameter stability/variability that is independent of the variability in the number of observations. Therefore, temporal stability/instability cannot be explained as a possible 
methodologically induced artifact of changing number of observations over time. But this method itself has the limitation that alternative sizes of the fixed temporal window (e.g. a window of eleven versus twenty-five years) could generate differing results. Each analysis may suggest something different about the general extent of stability or change as well as the particular historical location of changes in the estimated parameter structures because each time frame encompasses different historical conditions and events.

In general, because the forward and backward strategies follow a logic of expansive time periods while the diagonal approach operates with a fixed length temporal window, insights into a particular historical process gained by one approach can be buttressed by at least one of the others. Even when strong interest in either "developmental" or antecedent "structural shifts" are involved, the analyst would do well to supplement the forward or backward with the diagonal strategy. Irrespective of the particular combination of strategies, the greatest value of a TRR investigation will be achieved in conjunction with an intensive dialogue with historical sources.

\section{Temporal patterns in parameter regimes and their uses}

Because TRR allows the coefficients to change through time, the crosstemporal pattern of coefficients linking independent to dependent variables can indicate historical contingency due to changing contexts and timing of events. Any given explanatory variable in the specified model has a temporally unfolding parameter regime characterized by a shape that: (a) is relatively stable through time (parameter constancy); (b) changes abruptly at a particular moment in time (parameter shift); (c) changes in a gradual, incremental/decremental manner (parameter drift); or (d) follows a cyclical rhythm (parameter cyclicality). In multivariate models it is possible to have a mixed configuration of these patterns.

There are two basic ways in which these temporal parameter patterns may be employed: (a) as an aid in the process of periodization; and/or (b) as the object of analysis and explanation itself. The first is grounded in a contextualized version of time. If the coefficients indicate sufficiently clear discontinuities or shifts in temporal structure, they may warrant distinct periodization; that is, splitting the series into two or more distinct subperiods on which separate, historically contextualized time-series models might be estimated and compared. However, the process of periodization should not be limited to a narrow technical exercise; rather, empirical results should be used in conjunction with theoretical-historical evidence justifying the particular historical periodization in the process of interest.

When process temporality and the trajectory of relations are of interest, TRR coefficients can be converted to temporally local (e.g. year-specific) measures of relational impact. In this approach the cross-temporal pattern of localized coefficients become the phenomena to be explained and the 
nature of the research question shifts from what forces induce historical variation in a dependent variable to what social processes, conditions and events produce change in the relationships themselves. Hence, drifting, shifting or cyclical parameter trajectories become the object of analysis. At this point, the explanation could proceed in a strictly historical narrative mode and/or employ a second-order model to account for the crosstemporal variability in relations. Exactly how TRR results should be used will depend on the research question and analytic context. In our subsequent example, we illustrate both uses - periodization and cross-temporal parameter trajectories - of TRR results.

\section{Contributions to social historical inquiry}

TRR has substantial value for social historical inquiry that addresses questions with time-series data. In particular, TRR can be a useful analytic device because it historicizes time and facilitates access to time-dependent processes by: (a) forcing the analyst to think seriously about time frame, starting and ending points, and thorny issues associated with periodization; (b) allowing the analyst to uncover theoretically and historically significant turning points and qualitative breaks or shifts in patterns of determination; (c) emphasizing the necessity for access to the historical record; and (d) providing a way to integrate causal processes that follow patterns of longterm (slow) change with those that occur through short-term (rapid) transformative actions and events. ${ }^{10}$ The cross-movement impact of massive waves of insurgent actions provides a useful case in point.

\section{ANALYZING HISTORICAL PROCESS WITH}

TEMPORALLY RECURSIVE REGRESSION: CIVIL RIGHTS MOVEMENT SPILLOVER ON LABOR MILITANCY

In social movement scholarship, the study of intermovement relations and cross-movement influences is still largely underdeveloped. Very little systematic attention has been given to ways in which contemporaneously occurring movements shape political environments or become resources for each other in various cooperative or even incidental ways. One recent study begins to fill this void. "Inspired by David Meyer and Nancy Whittier's conceptual frame for analyzing intermovement "spillover", we illustrate the potential of temporally recursive regression by examining the dynamics of militancy spillover from civil rights movement street tactics into labor movement

Io. See William Sewell, "Collective Violence and Collective Loyalties in France", Politics \& Society, I8 (1990), pp. 527-552; Isaac and Leicht, "Regimes of Power", pp. 28-45.

II. David Meyer and Nancy Whittier, "Social Movement Spillover", Social Problems, 4I (1994), pp. $277-298$. 
militancy in the form of workplace strikes. We ask how post-war civil rights insurgencies influenced (if at all) the level of labor militancy. In other words, did the civil rights movement contribute to the "labor revolt" of the I960s and early i970s?

\section{Data and model specification}

All data used in the subsequent analysis are annual time-series observations for the United States spanning the years 1947 through 1981. We open with 1947 because that was the year in which the passage of the Taft-Hartley Act reorganized labor-management relations in a regime that increasingly privileged management's prerogative, ${ }^{12}$ helping to shut the window of opportunity for the labor-based civil rights movement that had emerged within parts of the dissident Congress of Industrial Organizations (CIO) during the 1930 s and $1940{ }^{13}{ }^{13}$ We close the analytic time frame with 1981 because it, too, marks another important turning point in the structure of labor-management relations. The first Reagan administration made its anti-labor position clear from the outset and quickly backed it up with a massive assault on the Professional Air Traffic Controllers Union. On more pragmatic grounds, the Reagan administration altered the standard definition employed in reporting annual aggregate strike data, with $198 \mathrm{I}$ marking the last year of the continuous definition. ${ }^{14}$

While labor militancy is clearly multidimensional, appearing in a variety of both open and subterranean forms, we limit the scope of our analysis by focusing exclusively on strike militancy in the public sector. We have demonstrated elsewhere that some key processes that shaped labor militancy over these decades, including civil rights insurgencies, differed importantly across sectors. ${ }^{15}$ Specifically, since the civil rights variables had no systematic influence on private sector militancy, we restrict our attention to the public sector patterns for this illustration.

Although we are primarily concerned with the spillover relations between civil rights and labor militancy, it is necessary to estimate these relations in the context of models that account for other important determinants of strikes. The major explanations for strike activity can be represented in four

12. For example, see Kim Moody, An Injury to All (London, 1988); Christopher Tomlins, The State and the Unions: Labor Relations, Law, and the Organized Labor Movement in America, $1880-$ 1960 (Cambridge, 1985).

13. See: Robert Korstad and Nelson Lichtenstein, "Opportunities Found and Lost: Labor, Radicals, and the Early Civil Rights Movement", Journal of American History, 75 (1988), pp. 786-8Ir; Michael Honey, Southern Labor and Black Civil Rights (Urbana, 1993).

14. P.K. Edwards, "The End of American Strike Statistics", British Journal of Industrial Relations, 21 (1983), pp. 392-394.

I5. Larry Isaac, Larry Christiansen, Jamie Miller and Tim Nickel, "Intermovement Relations: Civil Rights Movement Spillover on Labor Militancy in the Postwar United States", Paper to be presented at the American Sociological Association Meetings (San Francisco, 1998). 
basic categories: ${ }^{16}$ (I) organizational and resource strength; (2) labor market conditions and economic hardship; (3) legal-institutional framework of industrial relations; and (4) political environment or opportunity structure. In addition to constructing variables that tap each of these dimensions, we incorporate, as our central focus, measures of insurgency in the civil rights social movement field as a fifth category of partial derermination. Variables associated with each theoretical category, definitions and data sources are reported in the Appendix.

\section{Full period time-invariant patterns}

We begin by presenting the regression results for the entire period under study, $1947-1981,{ }^{17}$ shown in the last rows of Panels A and B of Table I. This step will aid in orienting the reader to the model structure and the general interpretation created by the conventional time-series approach. The Durbin-Watson statistic ${ }^{18}$ from the initial OLS estimates suggested problematic serial correlation, so we re-estimated with an appropriate GLS alternative. These unstandardized coefficients and t-ratios are presented in equation $\mathrm{I}$ :

$$
\begin{aligned}
& \text { [I] } \operatorname{PSSD}_{\mathrm{t}}=-10.30+.96 \mathrm{UDEN}_{\mathrm{t}-1}+.60 \mathrm{UNEM}_{\mathrm{t}}+.0 \mathrm{II} \mathrm{WAGE}_{\mathrm{t}}+ \\
& (3.34)^{*}(5.66)^{*} \\
& \text { (.24) } \\
& \begin{array}{llll}
(.98) & (.54) \quad(-\mathrm{I} .90) & (3.02)^{*}
\end{array}
\end{aligned}
$$

Period: $1948-198 \mathrm{I}$; Adj $\mathrm{R}^{2}=.84$; Estimator $=$ GLS-MA(I).

Equation I suggests that union density (UDEN) and black urban revolts (REVOLTS) contributed to strike density in the public sector (PSSD) over the whole time frame, while labor market conditions, institutional/electoral politics and protest demonstrations were all seemingly unimportant. However, this time-invariant strategy masks potential heterogeneity in causes of labor militancy. Given that protest waves are by definition highly explosive, nonlinear processes, and that the pace of insurgent actions inside movements is highly irregular, homogenizing assumptions that imply constant cross-temporal impact of urban revolts and the consistent null influence of civil rights protests appear suspect on historical grounds.

\section{Temporally recursive regression analysis}

We now relax the process homogeneity and fixed time frame assumptions that yielded the time-invariant results in equation I. Table 2 reports TRR

16. Roberto Franzosi, The Puzzle of Strikes (Cambridge, 1995).

17. The first year, 1947, is lost due to the lag structure of the model.

I8. OLS estimation assumes that the etrors across cases (years) are independent. If that assumption is violated, the standard errors associated with the regression coefficients are biased downward and hence the t-tests for significance become biased upwards. The Durbin-Watson " $\mathrm{d}$ " statistic tests 
estimates for our strike model. Although we draw on information from diagonal- and backward-moving strategies, we primarily employ a forwardmoving approach as our central concern is the developmental sequence and temporal trajectory of the model's parameter regime. In particular, we focus on how the influence of civil rights movement militancy (both PROTESTS and REVOLTS) on labor militancy unfolded over time.

Historically contingent processes - understood as cross-temporal change in relation magnitudes - are apparent in Table 2. Note that the full period (1948-198I) results in equation I indicate that only union density and rebellions have significant impacts on public sector strike density. However, when we scan the temporal windows in Table 2, it is clear that none of the explanatory variables in the model show consistently significant or null effects across time. None is even consistently signed over the full time period. Hence, the full period results, constrained to be time-invariant, mask important historical contingencies in all processes represented in the model of public sector strikes.

Union density, for example, shows contradictory influences on public sector strike activity over time. In the early part of the period (through 1962), union density hinders strike activity. The relation is reversed when the 1970 are brought into the analytic frame as union density appears to begin fostering strike activity. Abrupt parameter shifts are also evident in the variables measuring economic conditions. Unemployment and wage deprivation show positive, significant coefficients only in very limited time periods. Both legal-institutional and electoral environments influence strikes in historically contingent ways. Throughout the 1960s, public sector labor militancy was dampened by PL 330 and promoted by Democratic party strength. By the 1970s, however, these two processes appear to lose their causal efficacy.

The parameter regimes of the civil rights movement insurgencies also shift in important ways: protests stimulate strikes (as hypothesized) but only up through 1965 (coefficients range between .005 and .007), while urban ghetto revolts foster labor militancy only when historical experience beyond 1965 (the coefficient for 1948-1966 is .38) became part of the estimation record. These patterns clearly demonstrate the historically contingent quality of processes shaping public sector strike militancy in ways that could not have been revealed (and likely would not have been considered) within a conventional regression context.

\section{Periodization}

Are these patterns representative of real historical discontinuities, real heterogeneity, or are they perhaps simply chance fluctuations? As we indicated

the null hypothesis of no first-order serial correlation among the errors. Consult any basic econometrics text for guidelines for interpreting the DW values. 


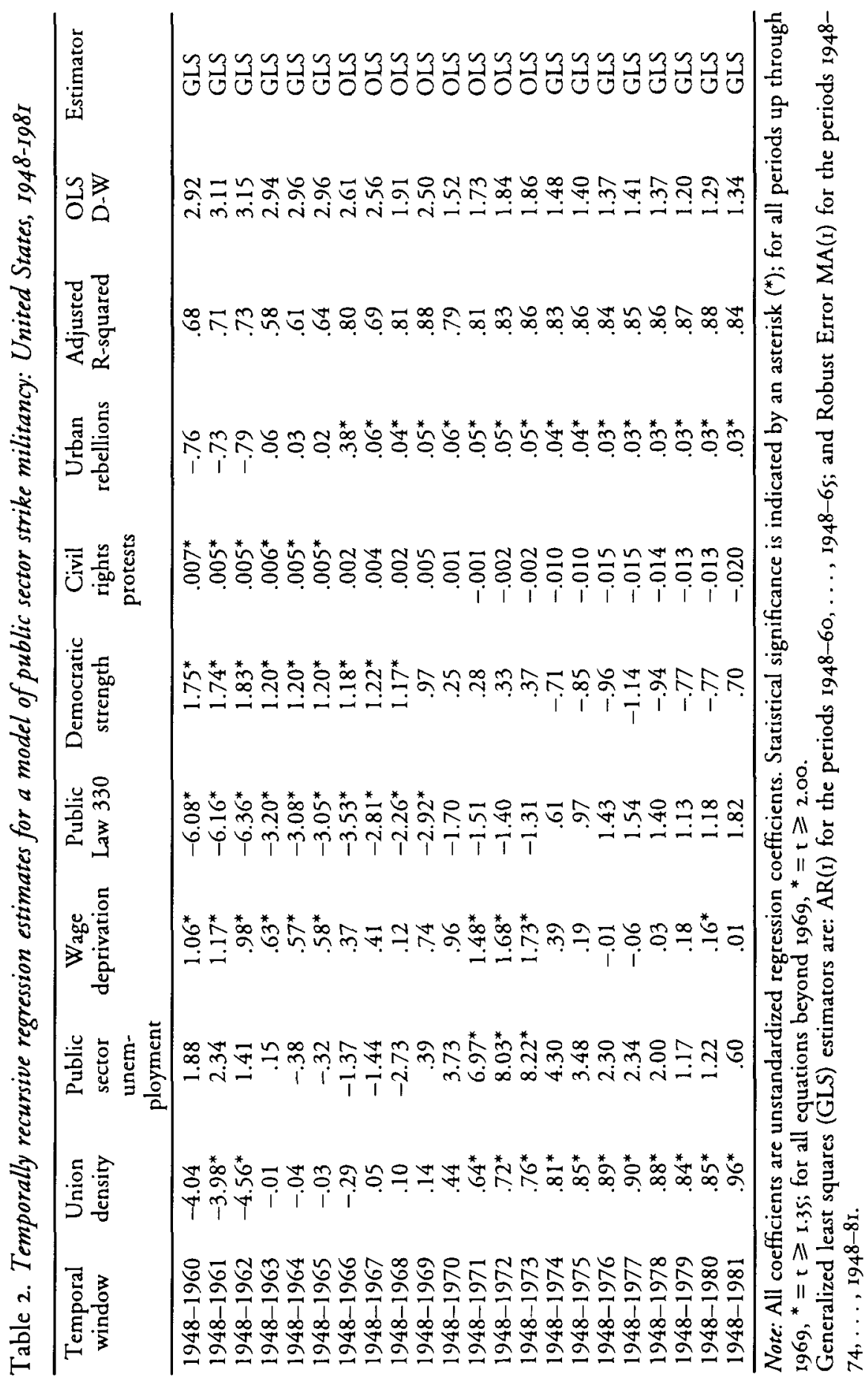




\section{Table 3. Period-specific estimates for public sector strike militancy}

\begin{tabular}{|c|c|c|}
\hline \multirow[t]{2}{*}{ Explanatory variables } & \multicolumn{2}{|c|}{ Historical periods ${ }^{2}$} \\
\hline & $1948-1969$ & $1970-1981$ \\
\hline Union density $(\mathrm{t}-1)$ & $.14^{\mathrm{b}}$ & -3.04 \\
\hline Unemployment $(t)$ & .39 & 6.24 \\
\hline Wage deprivation $(t-1)$ & .74 & -.18 \\
\hline Public Law $330(t)$ & $-2.92^{*}$ & $\ldots c$ \\
\hline Democratic Party $(t)$ & .97 & $9.26^{*}$ \\
\hline Protests $([\mathrm{t}]+[\mathrm{t}-1])$ & .01 & -.21 \\
\hline Urban revolts $([t]+[t-1])$ & $.05^{*}$ & .02 \\
\hline Constant & -14.02 & 104.12 \\
\hline Adjusted R-squared & .52 & .48 \\
\hline Durbin-Watson d & 1.83 & 1.99 \\
\hline Estimator & OLS & OLS \\
\hline
\end{tabular}

Notes:

The Chow test for differences between period-specific parameter regimes was statistically significant: $F=8.01$ (degrees of freedom $=7,20$ ) significant at $p=.0001$. F-tests for equivalence of protest and revolt slopes between periods were also significantly different.

${ }^{b}$ Unstandardized regression coefficients; * indicates coefficient at least twice its standard error.

" Public Law 330 is a constant for this period.

earlier, one of the basic uses of TRR results is to aid in the process of periodization. The issue is whether our time-series observations come from fundamentally different historical periods. Is there a point within our overall time frame in which one causal structure bifurcates into two (or more) regimes? We examined this question of structural shift using a variety of different forms of statistical evidence. Chow (F-) tests indicated statistically significant shifts (at probability levels of $\mathrm{p} \leq .02$ ) for each possible break point between 1969 and 1973 with the most salient break occurring between 1969 and $1970 .^{19}$

Table 3 reports the results of our public sector strike model estimated for the two historical periods (1948-1969 and 1970-198I) suggested by structural shift tests. Are these numerical differences historically explicable? The real

19. The Chow test is designed to test the homogeneity assumption as null hypothesis. In other words, when applied to the estimates for the two periods in Table 3, it gives an F-test statistic that gauges whether the coefficients in the two periods belong to the same overall historical period - 1948 to 1981 - or to two separate historical sub-periods. For a discussion of the Chow test, see Gregory C. Chow, "Tests of Equality Between Sets of Coefficients in Two Linear Regressions", Econometrica, 28 (1960), pp. 591-605, or consult any standard econometrics text. We examined other evidence for heterogeneiry, including: TRR patterns for the backward-and diagonal-moving (employing II-year windows as in Table I, Panel C) strategies; F-tests on contrasts between protest and revolt slopes from the full period model and forward-moving TRR patterns; and Quandr's $\log$-likelihood ratio procedure. All evidence suggested that the most significant break point was located within the 1969 to $197 \mathrm{I}$ period. 
issue here is the social historical significance of these patterns and inferences and such questions cannot be addressed by simply pointing to the coefficients themselves or even to the statistical significance of their differences across time. We believe the pronounced historical variability across the two period-specific equations in Table 3 is, in fact, historically significant and theoretically interpretable, representative of important social change in movement activity and in key institutions. We will return to the issue of social historical interpretation below.

\section{Temporally local effect trajectories}

The main question underlying the estimates presented in Table 3 continues to be what factors account for variation in public sector strike militancy within different historical contexts. But the TRR results can also be employed to gauge more temporally local influence. Such an approach is useful when the analysis focuses on the temporal trajectory of specific relations. For example, what does the trajectory of annualized influences of PROTESTS and REVOLTS on labor militancy look like over our time frame? What social processes, historical contexts and events alter the contour of these relationships?

There are a variety of ways to estimate temporally local influence. Using the forward-moving TRR results, we employ year-specific elasticities ${ }^{20}$ as our annualized measure of militancy spillover. This strategy is simultaneously sensitive to changing parameter regimes as well as the relative pace ${ }^{21}$ of insurgent activities and labor militancy at each moment (year) in time. It is especially useful for gauging historical contingency as temporally local effects in analyses where the temporal pace of collective actions matters and varies dramarically through history. The result allows an overall view

20. Elasticities are interpreted as the percentage increase in the dependent variable that results from a I per cent increase in the independent variable and are usually formed as the product of the unstandardized regression coefficient times the ratio of the mean of the independent to the mean of the dependent variable. But they can be evaluated at other points in the distributions, too. In algebraic terms, the year-specific elasticities derived from TRR results are defined as: $e_{\mathrm{yx}(t)}=$ $\mathrm{b}_{\mathrm{yx}_{\mathrm{x}(\mathrm{c})}}{ }^{*}\left(\mathrm{x}_{\mathrm{t}} / \mathrm{y}_{\mathrm{t}}\right)$. This is a modification of the implications of nonlinear regression models discussed in Ross Stolzenberg, "The Measurement and Decomposition of Causal Effects in Nonlinear and Nonadditive Models”, in Karl F. Schuessler (ed.), Sociological Methodology 1980 (San Francisco, 1980), pp. 459-488. The year-specific elasticity scales the TRR regression coefficient in a yearspecific (i.e. temporally local) manner rather than the conventional practice of scaling by the global moments of the respective distributions of $X$ and $Y$ (e.g. means for conventional elasticities or standard deviations for standardized regression coefficients).

2x. "Pace", or the frequency of action or events within a given time period, is one of the key temporal dimensions of social action central to historical sociological inquiry: see Ron Aminzade, "Historical Sociology and Time", Sociological Methods and Research, 20 (1992), pp. 456-480. 
of the process relations while preserving the temporally-specific elements that give protest waves their typically explosive and nonlinear qualities. ${ }^{22}$

Year-specific elasticities for the spillover impact of civil rights insurgencies on public sector labor militancy are mapped in Figure I. The cross-temporal trajectories for both protests are strikingly nonlinear. For example, the peak spillover year for PROTESTS was 1961. In that year labor militancy increased approximately 1.6 per cent for each I per cent increase in PROTESTS. In many other years - those prior to 1960 and those after $1965-$ the elasticities were effectively zero. Protest effects are largely concentrated between 1960 and 1965 , the heyday of the Southern civil rights movement, and decline dramatically after $1965 .{ }^{23}$ The urban ghetto revolt effect on public sector militancy explodes in 1966 and weakens gradually from 1967 through $1973,{ }^{24}$ the period in which the Black Power phase of the movement was strongest. The labor militancy-inducing influence dies out after that point.

The results in Figure I illustrate a simple but important point: for a social movement to produce substantial militancy spillover on the collective actions of other social movements, substantial levels of militant action may be required, perhaps even major waves of such action. McAdam ${ }^{25}$ has argued that the pace of a social movement - its ability to mobilize resources, sustain critical consciousness and maintain the overall energy of the struggle - is heavily dependent on "tactical innovation", the ability of movement participants to produce novel forms of collective action that catch the countermovement forces off-balance, garner successes, and inspire continuing participation and resource flows. In tandem, PROTESTS and REVOLTS contributed significant militancy spillover from the streets into the public sector workplace for the entire decade of the 1960s and into at least the early 1970 s.

22. On the wave character of movements, see Sidney Tarrow, The Power of Movement, (Cambridge, 1994); Doug McAdam, "Tactical Innovation and the Pace of Insurgency", American Sociological Review, 48 (1983), pp. 735-754; Larry W. Isaac, Debra Street and Stan Knapp, "Analyzing Historical Contingency with Formal Methods: The Case of the 'Relief Explosion' and 1968", Sociological Methods and Research, 23 (I994), pp. II4-I4I.

23. See Doug McAdam, Political Process and the Development of Black Insurgency 1930-1970, (Chicago, 1982).

24. Note that the patterning of the urban revolt effects on labor militancy die out when mapped with the year-specific elasticities (Figure 1), but appear to persist all the way through the 1970 in the forward-moving TRR results (Table 2). This difference rests on the way the year-specific elasticities rely directly on annual pace of insurgency to estimate an effect while the TRR coefficients alone are estimated across a series of years. The petering out of the revolt effects is also consistent with patterns from backward-moving regressions, which are not shown here except for the 1970-1981 period results shown in Table 3.

25. McAdam, "Tactical Innovation". 


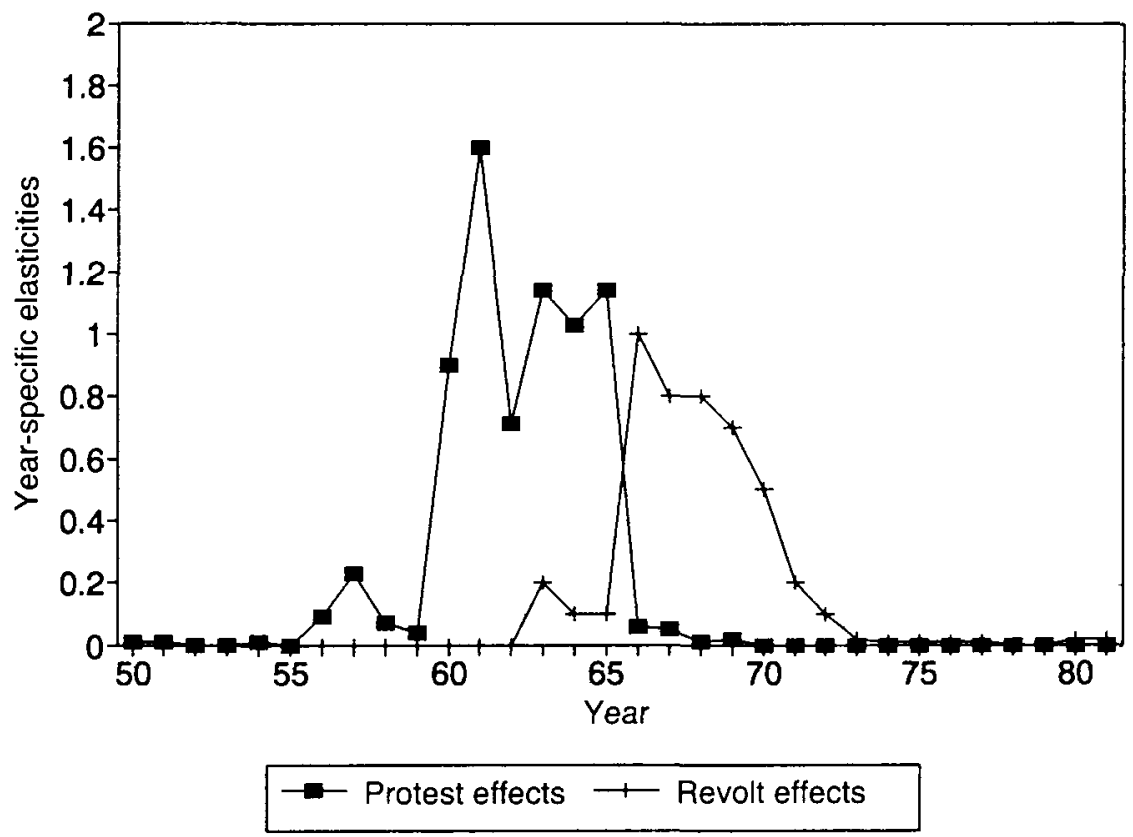

Figure I. Civil rights movement spillover effects (US public sector strike militancy)

\section{Periodization again}

How do we interpret the preponderance of evidence to this point? To answer this question we return to the issue of periodization first raised in discussion of Table 3. The contour of the localized influences of PROTESTS and REVOLTS (Figure I), the TRR results through the early I96os (Table 2) and the historical record combine to suggest that the twofold periodization in Table 3 may be a bit too crude. In particular, we were concerned that the length of the first period (1948-1969) might jeopardize important historical change and nuance in the relations of interest as both key institutions and the civil rights movement changed through time.

Table 4 summarizes our findings on civil rights impact on labor militancy within a more refined periodization that breaks the 1948 to 1969 frame into two shorter sub-periods: 1948 to 1959 and 1960 to 1969 . In addition to the statistical information, this periodization is grounded in both the institutional configuration comprising changing phases in the industrial relations regime and in the development of the civil rights movement.

During the first period (1948-1959), the industrial relations regime was marked by a general "accord" between capital and labor that was designed, among other things, to contain labor militancy. At that point, the civil rights movement was in its early stages with much of the activity centered 
Table 4. Summary of civil rights insurgency effects on public sector labor militancy in more refined historical periods

\begin{tabular}{lccc}
\hline & \multicolumn{3}{c}{ Historical periods } \\
\hline Years $^{2}$ & $1948-1959$ & $1960-1969$ & $1970-1981$ \\
Regime phase $^{b}$ & Accord & Accord/slowdown & Slowdown/decay \\
Civil rights movement $^{\text {ive }}$ & Emergence & Heyday \& Black & Decline \& backlash \\
phase $^{\mathrm{c}} \quad$ Protests $^{\mathrm{d}}$ & $-\mathrm{NS}$ & Power & \\
\multicolumn{1}{c}{ Revolts $^{\mathrm{d}}$} & $-\mathrm{NS}$ & $+\mathrm{S}$ & $-\mathrm{NS}$ \\
\hline
\end{tabular}

Notes:

"The periodization is based on statistical and theoretical-historical information.

b The industrial relations "regime phases" - "accord", "accord/slowdown" and "slowdown/decay" - are based on D. Gordon, R. Edwards and M. Reich, Segmented Work, Divided Workers (Cambridge, 1982), ch. 5. Their periodization of the consolidation and break-up of the post-war industrial relations regime in the US is: "accord" between labor and capital (1948-1966), "slowdown" or transition phase (1967-1973), and "decay" of the regime (1974-early 1980 ).

"These designations refer to qualitatively distinct phases in the post-war civil rights movement: "emergence" during the 1950s; the "heyday" of the movement during the first half of the 1960s; and the Black Power phase during the last half of the 1960s; by the 1970 , the movement is in serious decline with beginnings of racial backlash against movement gains.

d "Protest" and "urban revolt" effects are summarized for each period with qualitative designations derived from the quantitative estimates: $-\mathrm{NS}=$ negative but not significant; $+\mathrm{NS}=$ positive but not significant; $-\mathrm{S}=$ negative and significant; and $+S=$ positive and significant.

on court-ordered desegregation actions and some community bus boycotts. The movement had not yet hit its massive insurgency take-off phase. Both the accord and low levels of mass insurgency account for the null PROTEST and REVOLT effects during this period.

By 1960, the mass insurgency phase of the movement had opened with the sit-ins, freedom rides, community protest tactics spreading like wildfire across the South. From 1960 to 1965 , heroic civil rights protests demonstrations to dismantle the long-standing politics of Jim Crow institutions were being launched at an astounding pace. It was during these years that public sector workers, including teachers, postal employees and others, were showing signs of becoming increasingly militant. ${ }^{26}$ In some locations it was becoming difficult to separate workers' struggles from civil rights struggles. The militant actions of municipal sanitation workers in Memphis during 1968 and the Charleston hospital workers a year later are just two of the more well-known examples of

26. Michael Goldfield, "Public Sector Union Growth", Policy Studies Journal (Winter 1990), pp. 404-420. 
such militant fusion. ${ }^{27}$ During the decade of the 1960 , both PROTESTS and REVOLTS had positive, significant effects on public sector labor militancy. Civil rights movement spillover was greatest when the movement was peaking and the accord was beginning to weaken.

The final period, 1970 to $198 \mathrm{I}$, is marked by further decline in the accords and "decay" after 1973 as the assault on labor grew. ${ }^{28}$ The civil rights movement itself had largely folded by 1970 and a growing racialized backlash against movement gains was beginning to appear. For example, by the early I970s there were signs that the Republican party was mounting a racialized political strategy to foster a deeper racial division among the electorate as a way to dampen support for the Democratic party. ${ }^{29}$ In 1971, the US Congress passed the Postal Service Reorganization Act to contain worker militancy that had spawned a massive general wildcat strike the previous year in which some of the most militant leaders were African-American men. The reorganization of the postal service contained a distinct worker fragmenting and racially divisive quality to it. ${ }^{30}$ Overall the serious decline in movement activity coupled with the rise of a racialized backlash appear to have been sufficient to offset the favorable conditions for worker militancy provided by further decay of the accord.

We began our illustration by asking if civil rights militancy might have spilled over into public sector workplaces of America to fuel the "labor revolt" of the 1960 s and early I970s. Although partial and preliminary, our evidence suggests an affirmative answer to that question. However, this spillover effect does not appear to have been an institutionally general or temporally even outgrowth of the civil rights movement. Instead, it was profoundly contingent in quality. The unevenness of militancy diffusion was contingent on the tactical form (PROTESTS and REVOLTS) and pace of collective action waves, historical context (phase of civil rights movement and industrial regime change), and economic sector. ${ }^{3 i}$ These findings should encourage further investigation and urge that a social movement hypothesis be added to the stock of standard strike theories.

27. On Memphis, see Joan Turner Beifuss, At The River I Stand: Memphis, The 1968 Strike, and Martin Luther King (New York, 1989); on Charleston, see Leon Fink and Brian Greenberg, Upheaval in the Quiet Zone: A History of Hospital Workers' Union, Local 1199 (Urbana, 1989).

28. See, for example, Rick Fantasia, "The Assault on American Labor", in George Ritzer and Craig Calhoun (eds), Social Problems (New York, 1993).

29. On the decline of the black movement, see McAdam, Political Process; on racialized politics, see Thomas Edsall and Mary Edsall, Chain Reaction (New York, 1992); Jill Quadagno, The Color of Welfare (New York, 1994).

30. Peter Rachleff, "Working the Fast Lane: Jobs, Technology, and Scientific Management in the U.S. Postal Service", Radical America, 16, I and 2 (1982).

3I. Other analyses, not reported here due to space limitations, indicated that militancy spillover did not take place in any systematic manner for the private sector as a whole: reported in Isaac et al., "Intermovement Relations". 


\section{IMPLICATIONS FOR SOCIAL HISTORICAL INQUIRY}

Relationships between social historical processes often change through time. When they are forced to be constant, when historical context and timing of important events are ignored, we miss crucial opportunities in social historical inquiry. TRR maps relationships between social processes in a way that allows them to change historically and pushes the analyst to be sensitive to context and timing of events.

What does this mean for social historical inquiry more broadly? We see several important implications. First, rather than reducing notions of causality to single coefficient magnitudes, TRR motivates attention to relations between quantitative variation and qualitative change, even discontinuity, in social processes. Allowing quantitative relations to change through time means removing the constraint of constant cross-temporal meaning in social actions and events. This, in turn, leads to a greater concern with the interpretive mode of social historical research.

Second, if one of the central challenges to social historical research is to integrate long-term, continuous, social processes with faster-moving, shorter-term (even explosive) events, then TRR offers one potential bridge over this analytic gulf. ${ }^{32}$ Long-term trends, medium-term periodizations and transformative events can all be represented in TRR models.

Third, in promoting concern with the relation between the temporally general and temporally particular, TRR centers attention on specific time points as "unusual" (or "deviant") cases. Identifying such time periods creates the opportunity to theorize, for example, a particular year as a moment in which a conjuncture of events produced a transformation in a particular regime or other social arrangement. This dual focus allows generality to be informed by historical grounding in transformative moments while the uniqueness of those moments is also preserved. Within the context of quantitative time-series analyses, TRR generally allows greater access to an "eventful temporality"."

Fourth, the forms of causality that can be mapped with TRR afford the analyst greater opportunities for narrative flexibility in the explanation of historical processes. Theorizing historical contingency as temporally heterogeneous parameters points the narrative away from a representation of historical process as simple seamless linear continuity. TRR's potential for capturing changing nonlinear relations in historical process refocuses attention on human agency in social change by emphasizing indeterminacy and opportunities for creative action. Social movements, and the relations between them, are perhaps among the most dramatic examples of this kind of social historical process.

Finally, these methodological implications are consistent with much of

32. Sewell, "Collective Violence and Collective Loyalties"; Isaac and Leicht, "Regimes of Power". 33. Sewell, "Three Temporalities". 
the redirection or "historical turn" that has marked the contemporary human sciences. This redirection has developed from the theoretical reconfiguration of time, causality and narrative in social historical inquiry. The primary achievement of TRR in this effort is, we believe, its capacity to allow concrete (i.e. temporally local) conditions of social organization to play their role in a mode of argument that integrates the determinant and contingent, the explanatory and interpretive, in the study of social historical process. $^{34}$

Although far from resolving all the thorny issues of social historical inquiry, and in fact raising many new problems that the analyst must address, TRR strategies create opportunities that are otherwise closed-off by methodological fiat in conventional time-series practice. None of what we have identified as merits of this approach result automatically from applying a new technique. TRR has been available for over two decades and others have applied these procedures without invoking the significance of historical time nor the historicization of methods as a goal. However, by grounding its use in understandings of historical time combined with detailed forays into relevant historical records, we can exploit TRR's potential for historical exploration and explanation, thereby moderating some of the ahistorical features that plague conventional time-series analysis. We believe that this can contribute to both better quantitative social historical research and the kind of social theory that can explain and interpret concrete historical processes and events.

\section{APPENDIX. VARIABLE DEFINITIONS AND DATA SOURCES}

Public Sector Strike Density: Number of strikes per million workers in the public sector (federal, state, local) labor force. Source: AWS.

I. Organizational Resource Strength

Public Sector Union Density: Percentage of the public sector labor force unionized. Source: HS, SA.

\section{Labor Market Conditions and Economic Hardship}

Public Sector Unemployment: Percentage of the public sector labor force unemployed. Source: HS, SA.

Wage Deprivation: Public sector average annual wage as a percentage of unionized private sector average annual wage + percentage decline in public sector average annual real wages for decline years (non-decline years coded zero). Source: constructed from data in HS, SA, SCB.

34. Isaac, "Transforming Localities". 


\section{Legal-Institutional Framework of Labor-Management Relations}

Public Law 330: Binary variable indicating the pre- and post-"Public Law 330 " passed in 1955. PL 330 made it a felony to strike, to assert the right to strike, or to belong to an organization that asserts the right to strike; 1948I954 = 0; $1955-198 \mathrm{r}=$ I. Source: constructed from Goldfield.

\section{Electoral Political Environment}

Democratic Party Office Strength: Sum of (a) House (= proportion of nonDixiecrat Democratic representatives $+\mathrm{I}$ if Democrats were the majority in the House; (b) Senate (= proportion of non-Dixiecrat Democratic senators $+\mathrm{I}$ if Democrats were the majority in the Senate; and (c) Presidency (= I for Democrat; o for Republican). "Dixiecrat" is defined as those legislators from Southern, "right-to-work" states. Source: constructed from data in HS, SA.

\section{Civil Rights Movement Field}

Protests: Two-year moving sum $([\mathrm{t}]+[\mathrm{t}-\mathrm{I}])$ of the annual pace or frequency of civil rights protest demonstrations. "Protest" is defined (following Burstein) as a "public, manifestly political action by at least five people on behalf of the rights of minorities". Source: NYTI.

Urban Revolts: Two-year moving sum $([\mathrm{t}]+[\mathrm{t}-\mathrm{I}])$ of the annual pace or frequency of black urban revolts ("riots"), defined (following Isaac and Kelly) as a black-initiated collective action with a minimum of thirty participants and some amount of violence and/or property damage. Source: NYTI.

\section{Data Source Abbreviations:}

AWS = US Bureau of Labor Statistics, Analysis of Work Stoppages.

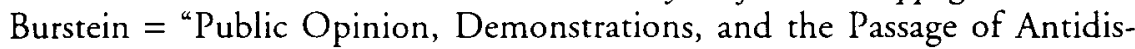
crimination Legislation", Public Opinion Quarterly, 43 (1979), pp. 157-172. Goldfield $=$ "Public Sector Union Growth and Public Policy", Policy Studies Journal, i8 (1990), pp. 404-420.

HS = US Bureau of the Census, Historical Statistics of the United States: Colonial Times to 1970.

Isaac and Kelly = "Racial Insurgency, the State, and Welfare Expansion", American Journal of Sociology, 86 (1981), pp. 1348-1386.

NYTI = New York Times, Annual Index.

$\mathrm{SA}=\mathrm{US}$ Bureau of the Census, Statistical Abstract of the United States.

$\mathrm{SCB}=$ Bureau of Economic Analysis, Survey of Current Business. 


\section{ANNOTATED BIBLIOGRAPHY}

This selective bibliography contains only substantive applications of various TRR strategies. Major technical expositions are cited in footnotes 8 and 9.

Beck, E.M. and Stewart Tolnay, "The Killing Fields of the Deep South: The Market for Cotton and the Lynching of Blacks, 1882-1930", American Sociological Review, 55 (1990), pp. 526-539.

The authors employ a diagonal-moving TRR strategy to map and interpret the temporal variability in the cotton price impact on the lynching of blacks in the deep South from 1882 to 1930.

Beck, Nathaniel, "Presidential Influence on the Federal Reserve in the 1970s", American Journal of Political Science, 26 (1982), pp. 415-445.

This paper examines presidential influence on Federal Reserve monetary policy in the 1970s. The author employs diagonal-moving TRR strategy as well as several tests for structural shifts.

Blau, Judith, "The Disjunctive History of U.S. Museums, 1869-1980", Social Forces, 70 (1991), pp. 87-106.

TRR is employed (but not presented) as an aid in periodizing the history of US museum foundings. The author uncovers and analyzes four distinct eras: 1869-1899, 1900-1930, 1931-1959 and 1960-1980.

Griffin, Larry J. and Larry W. Isaac, "Recursive Regression and the Historical Use of 'Time' in Time-Series Analysis of Historical Process”, Historical Methods, 25 (1992), pp. 166-179.

The authors discuss the basic rationale and logic of TRR strategies. Empirical analyses of US strikes and unionization processes between 1904 and 1945 are presented to illustrate the method.

Isaac, Larry W. and Larry J. Griffin, "Ahistoricism in Time-Series Analyses of Historical Process: Critique, Redirection, and Illustrations from U.S. Labor History", American Sociological Review, 54 (1989), pp. 873-890.

This paper lays the foundation for taking time and temporally-moving time-series approaches seriously in historical sociology. The authors illustrate their argument by analyzing examples of historical contingency in the US strike-unionization relation from the 1880 s to 1980 using temporally-moving covariance analysis.

Isaac, Larry W., Susan M. Carlson and Mary P. Mathis, "Quality of Quantity in Comparative/Historical Analysis: Temporally Changing Wage Labor Regimes in the United States and Sweden", in Thomas Janoski and Alexander Hicks (eds), The Comparative Political Economy of the Welfare State (Cambridge, 1994), pp. 93-135.

The authors argue that time-varying parameter approaches can be used to bridge the gulf between qualitative and quantitative analyses in comparative historical research. Empirical illustrations are presented using temporally-moving covariance analysis of the unemployment-wage 
relation in the context of changing regimes in Sweden and the United States.

Isaac, Larry W., Debra Street and Stan J. Knapp, "Analyzing Historical Contingency with Formal Methods: The Case of the 'Relief Explosion' and 1968", Sociological Methods \& Research, 23 (1994), pp. I14-I4I.

The authors argue that the forms of historical contingency captured by time-varying parameter models and those produced by event sequence approaches can be profitably combined. The argument is illustrated with a multi-level analysis of the "relief explosion" in the late 1960 S United States: event-structure analysis is used to unpack and interpret the sequence of events behind a major quantitative turning point revealed in a TRR analysis.

Isaac, Larry W. and Kevin T. Leicht, "Regimes of Power and the Power of Analytic Regimes: Explaining U.S. Military Procurement Keynesianism as Historical Process", Historical Methods, 30 (1997), pp. 28-45.

The authors highlight the importance of historical context and historical timing of events in explaining key aspects of US military spending during the cold war era. The empirical analysis features a forward-moving TRR approach that links a major quantitative turning point in the corporate profit-military spending relation to the McNamara-Kennedy reorganization of the Department of Defense. A second-order regression and historical narrative are employed to explain the cross-temporal variability in the key profit-military spending relation.

McCammon, Holly J., "From Repressive Intervention to Integrative Prevention: The U.S. State's Legal Management of Labor Militancy, I88I-1978”, Social Forces, 7I (1993), pp. 569-60I.

A variety of models of labor militancy are presented with key regression coefficients estimated and plotted from both forward- and backwardmoving TRRs. Tests for structural shifts are employed and major turning points in the mid-1930s are used to periodize models and explanations into pre- and post-Wagner Act eras.

Myers, Martha A., "Inequality and the Punishment of Minor Offenders in the Early 20th Century", Law \& Society Review, 27 (1993), pp. 313-343. The author uses a diagonal-moving TRR strategy to examine historical change in the effects of cotton price on incarceration rates in Georgia from the i890s to the 1930s. The cross-temporal effects are presented specific to race and form (chain gang versus penitentiary) of incarceration.

Rubin, Beth and Brian Smith, "Forged Ties: Cooperation and Conflict in the Metals Industry", Social Science Research, 2I (1992), pp. II5-I33.

The authors employ the logic of forward-moving TRR to an eventhistory analysis of strike settlements in the US primary metals industry from 1960 to 1977 .

Woolley, John T., "Partisan Manipulation of the Economy: Another Look 
at Monetary Policy with Moving Regression", Journal of Politics, 50 (1988), pp. 335-360.

The author studies presidential administration manipulation of economic policy employing diagonal-moving TRR. Primary focus is on the changing inflation and unemployment effects on the federal funds interest rate. The importance of timing of effects and TRR's capabilities in this regard are indicated. 